Original Article

\title{
Lowering the sintering temperature of solid oxide fuel cell electrolytes by infiltration
}

\author{
Can Sındıraç ${ }^{\mathrm{a}}$, Seda Çakırlar ${ }^{\mathrm{b}}$, Aligül Büyükaksoy, ${ }^{\mathrm{c}, \mathrm{d}}$, Sedat Akkurt ${ }^{\mathrm{a}, *}$ \\ a Izmir Institute of Technology, Department of Mechanical Engineering, Turkey \\ ${ }^{\mathrm{b}}$ Izmir Institute of Technology, Department of Chemical Engineering, Turkey \\ ${ }^{c}$ Gebze Technical University, Department of Materials Science and Engineering, Turkey \\ ${ }^{\mathrm{d}}$ Gebze Technical University, Institute of Nanotechnology, Turkey
}

A R T I C L E IN F O

\section{Keywords:}

SOFC

GDC

Electrolyte

Microstructure

Densification

Infiltration

\begin{abstract}
A B S T R A C T
A dense electrolyte with a relative density of over $95 \%$ is vital to prevent gas leakage and thus the achievement of high open circuit voltage in solid oxide fuel cells (SOFCs). The densification process of ceria based electrolyte requires high temperatures heat treatment (i.e. $1400-1500{ }^{\circ} \mathrm{C}$ ). Thus, the minimum co-sintering temperatures of the anode-electrode bilayers are fixed at these values, resulting in coarse anode microstructures and consequently poor performance. The main purpose of this study is to densify gadolinia doped ceria (GDC), a common SOFC electrolyte, at temperatures lower than $1400^{\circ} \mathrm{C}$. By this aim, an approach involving the infiltration of polymeric precursors into porous electrolyte scaffolds, a method commonly used for composite SOFC electrodes, is proposed. By infiltrating polymeric precursors of GDC into porous GDC scaffolds, a reduction in the sintering temperature by at least $200{ }^{\circ} \mathrm{C}$ is achieved with no additives that might affect the electrical properties. Energy dispersive $\mathrm{x}$-ray spectroscopy line scan analyses performed on porous GDC scaffolds infiltrated by a marker solution (polymeric FeOx precursor in this case) reveals a homogeneous infiltrated phase distribution, demonstrating the effectiveness of polymeric precursors.
\end{abstract}

\section{Introduction}

Excessive use of fossil fuels and their effect on global warming requires the search for clean alternative energy sources [1,2]. Solid oxide fuel cells (SOFCs) have been attracting attention from researchers because of their ability to convert chemical energy into electrical energy without combustion $[3,4]$. Although SOFCs are one of the cleanest and most efficient power sources, the maximum power density achievable by these devices must be enhanced. This way their cost per power generated can be minimized [5-8].

SOFCs are operated at high temperatures $\left(600-1000^{\circ} \mathrm{C}\right)$ by having a constant supply of hydrogen and oxygen at the anode and cathode sides, respectively. Obviously, the two gases should not be intermixed to i) obtain high open circuit voltage and ii) avoid violent burn out [9-13]. This is achieved by having a dense gas tight ceramic electrolyte. In order to be perfectly gas leak-free, a $95 \%$ relative density is the generally accepted target. To achieve this relative density value, the most commonly used electrolytes, i.e., yttria stabilized zirconia (YSZ) and gadolinia doped Ceria (GDC) must be sintered at temperatures exceeding $1400^{\circ} \mathrm{C}$ [14-16]. This is problematic because the manufacturing process of SOFC requires that both electrolyte and electrode layers be sintered together while in contact which is known as co-sintering [17]. Consequently, the sintering temperature of the anode is set at the densification temperature of the electrolyte. The high cosintering temperatures result in coarse anode microstructures, which correspond to short triple phase boundary length and thus, poor anode performance [16-20].

Another drawback related to the sintering of gadolinium doped ceria specifically, at high temperatures is the reduction of $\mathrm{CeO}_{2}$ to $\mathrm{Ce}_{2} \mathrm{O}_{3}$ due to unstable valance states of cerium from $\mathrm{Ce}^{+4}$ to $\mathrm{Ce}^{+3}$ which may cause the formation of micro-cracks [21-25]. Also, sintering the SOFC electrolytes at temperatures lower than $1400^{\circ} \mathrm{C}$ is also beneficial due to energy savings from lower temperature kiln heating.

The infiltration method has previously been proposed to form composite anode and cathode layers [25-29]. Use of polymeric $\mathrm{La}_{0.8} \mathrm{Sr}_{0.2} \mathrm{MnO}_{3}$ (LSM) [25] and $\mathrm{Ni}$ [26,27] precursors to infiltrate porous yttria stabilized zirconia (YSZ) scaffolds yielded LSM-YSZ and Ni-YSZ composite cathodes and anodes respectively with microstructures consisting of interconnected infiltrated films on the surfaces of YSZ particles. This, in turn, resulted in very promising electrode

\footnotetext{
* Corresponding author.

E-mail address: sedatakkurt@iyte.edu.tr (S. Akkurt).
} 


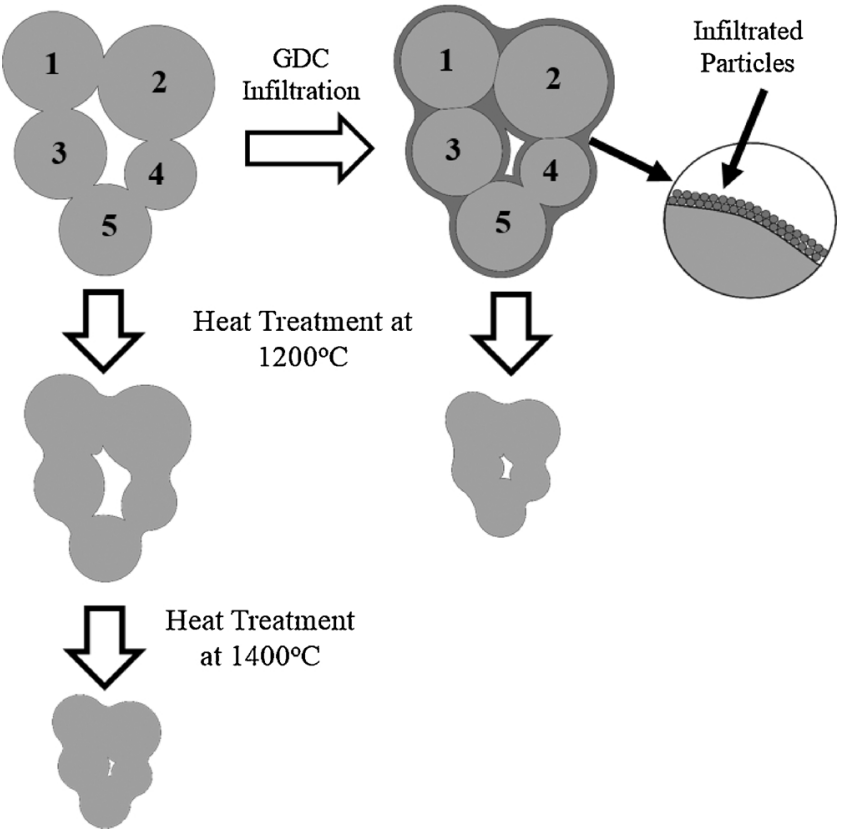

Fig. 1. Schematic representation of the sintering behavior of the consolidated gadolinia doped ceria (GDC) ceramic particles with and without polymeric GDC precursor infiltration. Here, the infiltrated GDC phase serves to i) form connections between particles that are otherwise uncoordinated (e.g., between particles 2 and 3), ii) increase the overall solids loading of the green body and iii) provide fast diffusion routes through its amorphous volume.

polarization resistances of $0.030 \Omega \mathrm{cm}^{2}$ [25] and $0.1 \Omega \mathrm{cm}^{2}$ [26,27] at $800{ }^{\circ} \mathrm{C}$ in the cathode and anode cases respectively.

In the present study, the use of the infiltration technique is proposed for low temperature densification of GDC electrolytes, for the first time in the literature. Here, a three-stage process is proposed, as depicted in Fig. 1. First, a GDC pellet is pre-sintered at a low temperature $\left(1000^{\circ} \mathrm{C}\right)$ to allow for the neck formation among the particles and obtain just enough strength for handling while retaining a large amount of porosity. The pre-sintered porous GDC ceramic will be referred to as the "porous scaffold" from now on. In the second stage, a polymeric precursor solution carrying fixed proportions of $\mathrm{Ce}^{4+}$ and $\mathrm{Gd}^{3+}$ ions is infiltrated into the pores of the scaffold and heated at $400{ }^{\circ} \mathrm{C}$ to drive off the solvent and the organics. This yields interconnected films of GDC on the particle surfaces. In the third stage, the infiltrated scaffold is subjected to a final sintering procedure at $1000-1200{ }^{\circ} \mathrm{C}$ to allow for solidstate diffusion to take place and to produce the final densified ceramic. The GDC films formed on the GDC particles of the porous scaffolds by infiltration is considered to enhance the sintering rate for three reasons. First, they fill some of the porosity and cause an increase in the density even before the final heat treatment process (Fig. 1). Second, they increase the coordination number of the scaffold particles that, i.e., form necks between particles were otherwise not in contact with each other (e.g., coordination of particles 2 and 3 in Fig. 1 upon infiltration). Finally, the amorphous nature of the films at the surface of the GDC particles provide a fast diffusion pathway and thus allow for activated sintering. The major advantage of the infiltration aided sintering process is the fact that the infiltrated solution contains the same cations as the host, i.e., no additives that may influence the electrical properties (as reported in Refs $[9,15]$ ) is required.

In the proposed lower temperature sintering process, it is obviously crucial that the infiltration of the GDC precursor is carried out effectively and homogenously throughout the whole volume of the porous GDC scaffold. Only then, differential sintering and consequent cracking may be avoided. In order to be able to track the distribution of the infiltrated phase within the porous scaffold by chemical analyses, i.e., to test the effectiveness of the infiltration process, polymeric precursors that contain cations other than $\mathrm{Gd}^{3+}$ and $\mathrm{Ce}^{4+}$ must be infiltrated into porous GDC scaffolds. Therefore, the use of an Fe bearing polymeric precursor solution (which will be referred to as polymeric FeOx precursor from then on) as an infiltrating liquid to serve as a marker is also planned (Fig. 1). The selection of Fe cation as an infiltration marker originates from the fact that oxides of Fe is a common GDC sintering aid and thus, the results obtained here can be compared to the reports in the literature $[9,20,30,31]$.

\section{Experimental methods}

\subsection{Fabrication of porous GDC scaffold electrolyte}

$10 \mathrm{~mol} \%$ gadolinium-doped ceria powder (denoted as GDC, $\mathrm{Ce}_{0.9} \mathrm{Gd}_{0.1} \mathrm{O}_{3}$, PRAXAIR $>99.9 \%$ ) was used for preparing the porous ceramic scaffolds. Specific surface area of this powder was $6.5 \mathrm{~m}^{2} / \mathrm{g}$ while the $d_{10}, d_{50}$ and $d_{95}$ values were $0.4 \mu \mathrm{m}, 0.5 \mu \mathrm{m}$ and $0.9 \mu \mathrm{m}$, respectively. The powder was pressed in a $15 \mathrm{~mm}$ diameter cylindrical stainless steel die by uniaxial pressing (Carver Hydraulic Press, Wabash, IN, USA) with $180 \mathrm{MPa}$ pressure.

The pellets were then fired to obtain a porous scaffold in an electrically heated laboratory kiln (Nabertherm LHT 02/17, Germany) at $1000{ }^{\circ} \mathrm{C}$ with $6 \mathrm{~h}$ of soaking time at a heating/cooling rate of $3{ }^{\circ} \mathrm{C} / \mathrm{min}$.

\subsection{Polymeric precursor solution preparation and infiltration process}

To densify the porous GDC scaffolds, GDC or Fe-oxide polymeric precursor solutions were used for infiltration. To prepare the polymeric GDC precursor; $\mathrm{Ce}\left(\mathrm{NO}_{3}\right)_{3} \cdot 6 \mathrm{H}_{2} \mathrm{O}$ (ALFA-AESAR > 99.5\%) and $\mathrm{Gd}$ $\left(\mathrm{NO}_{3}\right)_{3} \cdot 6 \mathrm{H}_{2} \mathrm{O}$ (Sigma-Aldrich $>99.9 \%$ ) salts were dissolved in deionized water at a cation molar ratio to obtain the $\mathrm{Ce}_{0.9} \mathrm{Gd}_{0.1} \mathrm{O}_{2-\delta}$ (GDC) stoichiometry. In the next step, the salt solution was mixed with ethylene glycol in different molar ratios i.e. cation/ethylene glycol molar ratios $=(0.020-0.080): 1$, and stirred at $\sim 80^{\circ} \mathrm{C}$ until all water evaporated and polymerization took place. For success of the inflitration process, the molar ratio of cations and ethylene glycol is considered as a significant factor to be studied. The determination of these ratios have been purely empirical. To avoid excessive infiltration/decomposition steps to achieve an acceptable amount of infiltrant loading, efforts were made to maximize the cation molarity which could be chelated to the polymeric chains, without increasing the viscosity to an extent that could inhibit the penetration of the final precursor into the porous scaffold. The solution was diluted with 2-butoxyethanol in order to ensure good wetting properties of GDC scaffold and for reducing the surface tension of the polymeric solutions.

Iron bearing polymeric precursor solution was prepared following a similar procedure but this time an aqueous solution of iron (III) nitrate nanohydrate (ALFA-AESAR > 99.99\%) salt was used. Further details of the process are given elsewhere [32-34].

Fig. 1(a)-(b) shows schematically the infiltration process of porous GDC by GDC and iron bearing precursor solutions, respectively. Porous GDC pellet that was pre-sintered at $1000^{\circ} \mathrm{C}$ for $6 \mathrm{~h}$, was immersed in the infiltration solution in a beaker before being placed in a desiccator which was evacuated by a laboratory vacuum pump (Lanphan 2XZ-2, Zhengzhou, Henan, China). Thereby, most of the bubbles entrapped in open pores were forced to leave the specimen and be placed by the polymeric solution. Next, the surface of the pellets were wiped with a paper towel, placed onto a hot plate and gradually heated to $400{ }^{\circ} \mathrm{C}$ until all solvent evaporated and organics burnt out. This procedure was repeated 25 or 35 times before the samples were subjected to a secondary heat treatment in an electrically heated kiln at different temperatures (e.g. $1000-1100-1200{ }^{\circ} \mathrm{C}$ ) for $8 \mathrm{~h}$. 


\subsection{Density measurement}

Bulk densities of the pellets were measured by Archimedes method according to ASTM C-20 standard [35]. After the density measurement of samples, relative density was estimated by using the Eq. (1):

$\%$ Relative Density $(\% R D)=\left(\mathrm{d}_{\mathrm{s}} / \mathrm{d}_{\text {th }}\right) \times 100$

where $d_{s}$ is the measured bulk density of sample and $d_{t h}$ is the theoretical density of GDC.

Theoretical density of $10 \mathrm{~mol} \%$ gadolinium doped ceria is taken as $7.2 \mathrm{~g} / \mathrm{cm}^{3}[36-38]$;

\subsection{Structural and microstructural characterization}

The crystal structures of samples were studied by X-Ray Diffraction (XRD, Panalytical X-Pert Pro). Cu Ka radiation was used as the X-ray source. Both the microstructural and compositional analysis of the noninfiltrated GDC and infiltrated GDC electrolyte samples were analyzed by Scanning Electron Microscopy (SEM, Philips XL 30S FEG) utilizing secondary electron (SE) imaging and Energy Dispersive X-Ray Spectroscopy (EDX).

\subsection{Coding of samples}

A coding scheme was used to help the reader better follow the manuscript. For example, the sample code 35-G-80-1200 represents a porous pellet that was infiltrated 35 times by a solution bearing $0.080 \mathrm{M}$ GDC before being sintered again at $1200^{\circ} \mathrm{C}$ for $8 \mathrm{~h}$. This coding scheme was explained in Table 1.

\section{Results and discussions}

\subsection{Crystal structure analyses}

The crystal structure of the gadolinia doped ceria (GDC) ceramics sintered conventionally or by using an infiltration-assisted approach were analyzed by x-ray diffraction (XRD), as shown in Fig. 2a-c. In the conventionally sintered GDC ceramics, all collected patterns appear to match well with the reference pattern for cubic GDC numbered JCPDF 01-075-0161 (Fig. 2a).

Porous GDC scaffolds infiltrated with different amounts of GDC, sintered at either $1000^{\circ} \mathrm{C}$ or $1200{ }^{\circ} \mathrm{C}$ consisted of the same GDC phase $\mathrm{Ce}_{0.9} \mathrm{Gd}_{0.1} \mathrm{O}_{1.95}$ with JCPDF number 01-075-0161, i.e., no new compound formation after infiltration and sintering is observed, as expected (Fig. 2b). When the porous GDC scaffolds are infiltrated by different amounts of polymeric $\mathrm{FeOx}$ precursor and heat treated at 1000 or $1100^{\circ} \mathrm{C}$, the second highest peak of the $\mathrm{Fe}_{2} \mathrm{O}_{3}$ peak at $2 \theta=35.6^{\circ}$ appears (PDF: 01-089-2810, Fig. 2c). When the sintering temperature is raised to $1200{ }^{\circ} \mathrm{C}$, peaks belonging to the compound $\mathrm{Fe}_{5} \mathrm{Gd}_{3} \mathrm{O}_{12}$ (PDF:00-013-0327) is also observed (Fig. 2c). Upon the introduction of a higher amount of FeOx into the porous GDC scaffold by infiltration, a higher amount of $\mathrm{Fe}_{5} \mathrm{Gd}_{3} \mathrm{O}_{12}$ phase is observed (Fig. 2c).

\subsection{Weight and density measurements}

For a clear analysis of the impact of the application of the infiltration method on the densification rate of GDC ceramics, a set of reference data on the conventional solid-state sintering behavior of the GDC ceramics is collected. The relative densities of the sintered GDC pellets, calculated using Eq. (1), are plotted as a function of sintering temperature in Fig. 3. As expected, the relative bulk density increases as the sintering temperature is increased. Only a slight difference in relative densities is observed upon sintering at the $800-1100^{\circ} \mathrm{C}$ temperature range. However, significant increase in the density takes place when sintering is performed at temperatures between 1100 and $1400{ }^{\circ} \mathrm{C}$, indicating a typical solid-state sintering behavior. In this same range, densification rate was higher as well. Highly dense (>95\% RD) GDC ceramics that are directly applicable as SOFC electrolytes is obtained upon sintering at temperatures over $1400^{\circ} \mathrm{C}$.

Infiltration of polymeric GDC precursors into porous GDC pellets were performed to enhance the coordination among the GDC particles and increase the solids loading to maximize the green density and thus reduce the sintering temperature at which at least $95 \%$ relative density is achieved. The purpose was obviously to minimize the diffusion distances necessary for densification. The infiltration of polymeric GDC precursors were performed into porous GDC pellets with approximately $40 \%$ porosity (i.e., $60 \%$ density), obtained by pre-sintering at $1000{ }^{\circ} \mathrm{C}$ for $6 \mathrm{~h}$.

GDC infiltration parameters, such as; the molarity of infiltration solutions, the number of infiltration cycles and the final sintering temperature were varied to observe their effect on the sintering behavior and finally achieve high relative final density at lower sintering temperatures (Fig. 4). Each experimental run was replicated three times to weigh the error of the density measurement, which turned out to be very low (less than $0.8 \%$ ). After each polymeric GDC infiltration and decomposition at $400{ }^{\circ} \mathrm{C}$ (i.e., one complete infiltration cycle) the weight of the porous scaffold was measured in order to determine the amount of GDC formed inside the porous scaffold and the rate at which the pores are being filled. Fig. 4a depicts that all pellets consistently gained weight as the number of infiltration cycles increased (Fig. 4a). As expected, when the polymeric GDC precursors with higher molarity of cations are used for infiltration, the weight increases with a more steep slope with increasing number of infiltration cycles (Fig. 4a). It is also worth noting that the weight gain followed a somewhat linear trend in all cases, suggesting that neither clogging of the pores, nor reaching the maximum possible infiltration amount is taking place.

At the core of this study is an effort to maximize the density of GDC pellets by sintering at temperatures lower than the convention suggests. Therefore, the effects of the sintering temperature, number of infiltration cycles and the molarity of the infiltrating solution on final sintered density were studied. The relative densities of the porous GDC scaffolds infiltrated by polymeric GDC precursors with molarities ranging from 0.040 to $0.080 \mathrm{M}$ for 25 or 35 cycles, subjected to a final sintering

Table 1

Table showing the processing parameters and the corresponding sample codes.

\begin{tabular}{|c|c|c|c|c|}
\hline \multirow[b]{2}{*}{ Code Number } & \multicolumn{3}{|l|}{ Infiltration } & \multirow{2}{*}{$\begin{array}{l}\text { Final Sintering } \\
\text { Temperature }\left({ }^{\circ} \mathrm{C}\right)\end{array}$} \\
\hline & Number of Cycles & Solution Type & Concentration (M) & \\
\hline $25-G-40-1000$ & 25 & GDC & 0.040 & 1000 \\
\hline $25-G-40-1200$ & 25 & GDC & 0.040 & 1200 \\
\hline $35-G-40-1200$ & 35 & GDC & 0.040 & 1200 \\
\hline $35-G-80-1200$ & 35 & GDC & 0.080 & 1200 \\
\hline 25-F-15-1000 & 25 & $\mathrm{Fe}$ & 0.015 & 1000 \\
\hline 25-F-15-1200 & 25 & $\mathrm{Fe}$ & 0.015 & 1200 \\
\hline 25-F-20-1200 & 25 & $\mathrm{Fe}$ & 0.020 & 1200 \\
\hline $35-F-20-1200$ & 35 & $\mathrm{Fe}$ & 0.020 & 1200 \\
\hline
\end{tabular}



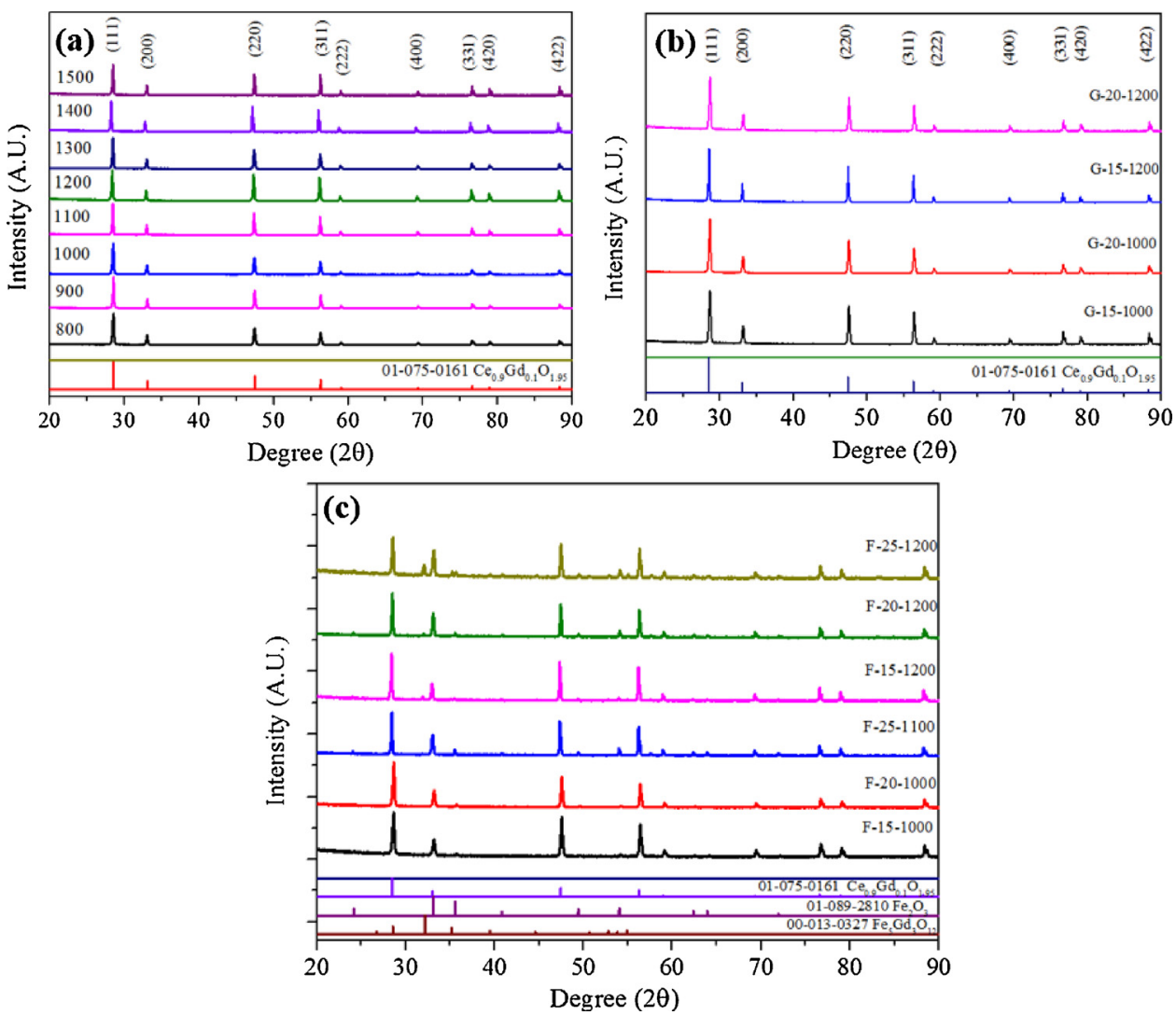

Fig. 2. X-ray diffraction patterns of a) blank, b) 15 or 20 times gadolinia doped ceria (GDC) infiltrated and c) 15, 20 or 25 times FeOx infiltrated GDC pellets sintered at $800-1500^{\circ} \mathrm{C}$ (a) or $1000-1200{ }^{\circ} \mathrm{C}(\mathrm{b}$ and c).

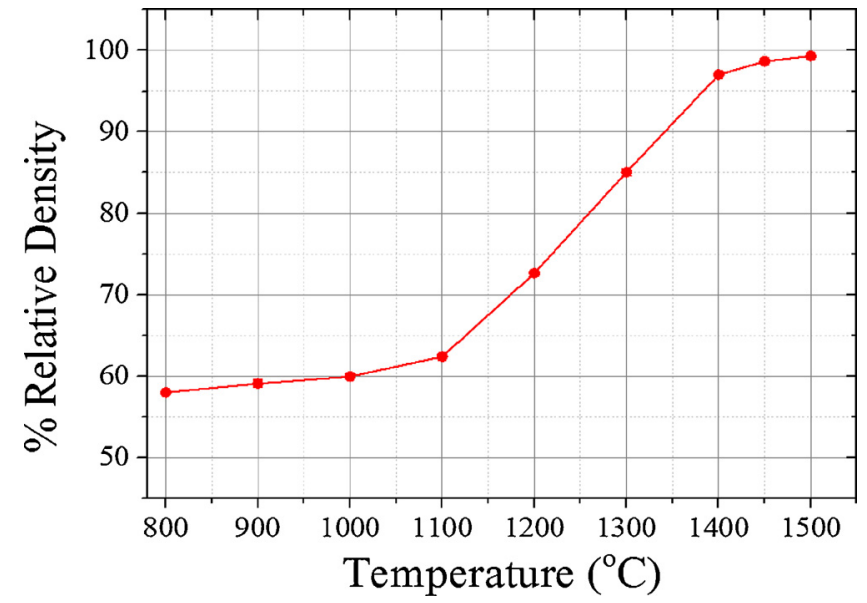

Fig. 3. Effect of the sintering temperature on the relative density of the gadolinia doped ceria pellets. The sintering procedure was performed for $8 \mathrm{~h}$ in stagnant air.

procedure at 1000 or $1200{ }^{\circ} \mathrm{C}$ are provided in Fig. 4b. GDC infiltrated porous GDC scaffolds reached relative density values ranging from ca. $73 \%$ to $84 \%$, depending on the number of GDC infiltration cycles and the polymeric precursor solution molarity upon being subjected to a final sintering procedure at $1000{ }^{\circ} \mathrm{C}$ for $8 \mathrm{~h}$. Increasing the amount of infiltration cycles and the polymeric precursor molarity, in other words, increasing the infiltrated GDC content appears to increase the obtained relative density upon final sintering at $1000^{\circ} \mathrm{C}$. Raising the final sintering temperature to $1200^{\circ} \mathrm{C}$ results in a further increase in the final relative density in all samples, allowing the achievement of a relative density value in excess of $95 \%$ in the case of the sample infiltrated by a polymeric GDC precursor with a molarity of $0.080 \mathrm{M}$ for 35 cycles (35G-80). It should be noted that by conventional solid-state sintering at $1200{ }^{\circ} \mathrm{C}$, a relative density value of only $75 \%$ was achieved and a $95 \%$ relative density was possible only when sintering temperatures exceeding $1400^{\circ} \mathrm{C}$ were used (Fig. 3). Therefore, significant savings in final sintering temperatures were successfully achieved.

Fig. 4c more clearly shows the effect of precursor solution molarity on the final density. In the case of samples subjected to a final sintering procedure at $1200^{\circ} \mathrm{C}$ infiltrated by polymeric GDC precursors for 25 or 35 cycles, the final relative densities increase significantly when the solution molarity is increased from 0.020 to $0.080 \mathrm{M}$. In both cases of 25 or 35 cycles of infiltration, a plateau is almost reached at $0.080 \mathrm{M}$. Since, on the other hand, the weight gain still continues linearly at precursor molarities of $0.080 \mathrm{M}$ even after 25 cycles of infiltration (Fig. 4a), it can be suggested that although further GDC infiltration can still fill the pores of the scaffold, it can no longer connect the uncoordinated GDC particles of the porous GDC scaffold (Fig. 4c).

The same parameters used in GDC infiltration were also investigated for FeOx infiltration. Fig. 5a shows that increasing the number of infiltration cycles leads to a linear weight increase with no apparent saturation trend. Also, the use of polymeric FeOx precursor solution with a higher molarity results in a steeper weight gain, in a similar trend observed in GDC infiltration (Fig. 5a).

FeOx infiltrated ceramics densified at even lower temperatures than the GDC infiltrated samples did (Fig. 5b). For example, densities higher than $96 \%$ could be easily reached even after heat treating at $1100^{\circ} \mathrm{C}$ (Fig. 5b). The reason for the faster densification observed in the FeOx infiltrated GDC ceramics than those infiltrated with GDC lies in the difference between the densification mechanisms GDC and FeOx infiltrations have to offer. The infiltrated $\mathrm{FeOx}$ phase forms films on the particles of the GDC scaffolds and functions as a sintering aid by viscous sintering $[39,40]$. Efforts to load more $\mathrm{FeOx}$ inside the pores by 

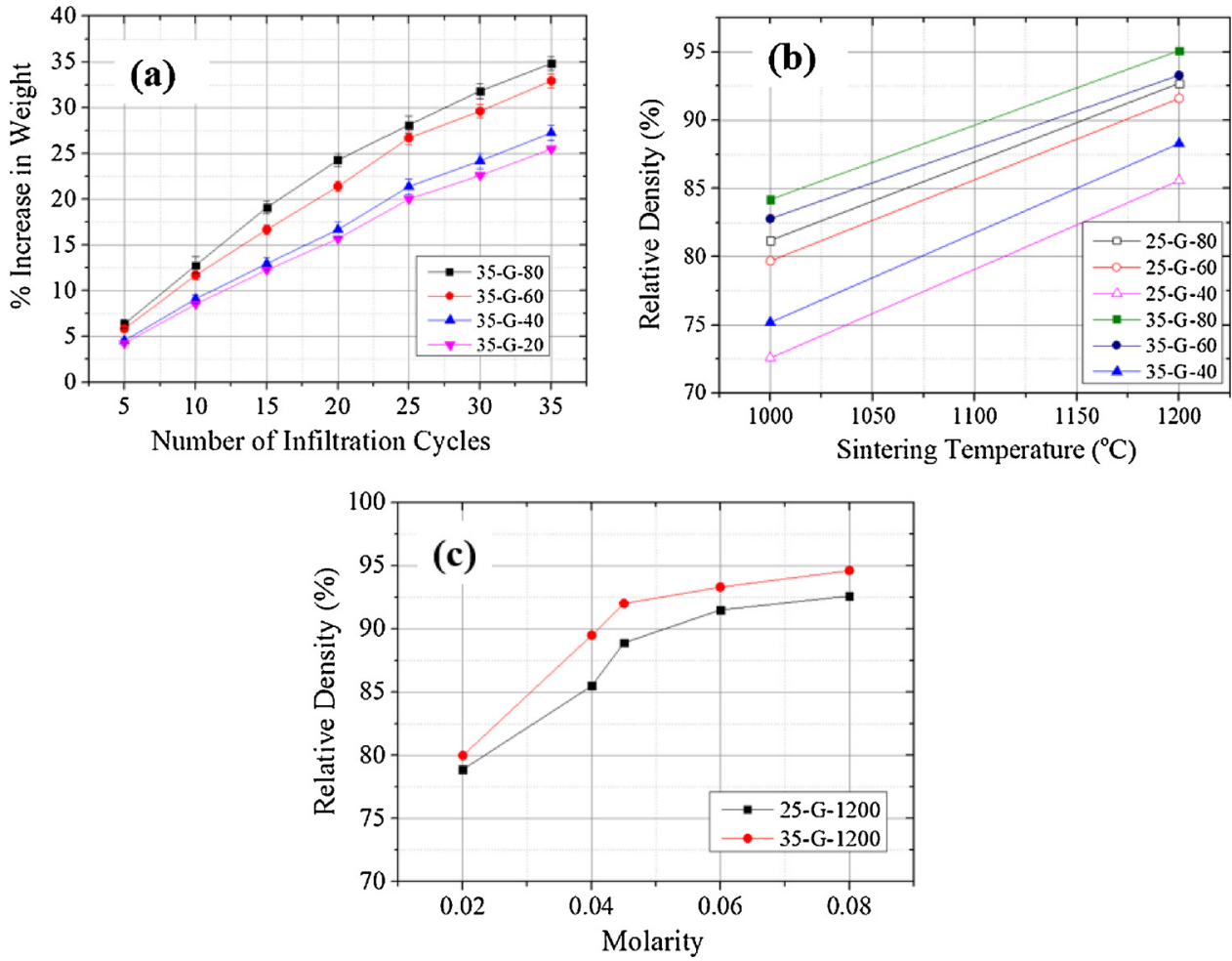

Fig. 4. a) Effect of polymeric gadolinia doped ceria (GDC) precursor infiltration cycles on the $\%$ weight increase of the porous GDC scaffolds when 0.02 (35-G-20), 0.04 (35-G-40), 0.06 (35-G-60) and $0.08 \mathrm{M}$ (35-G-80) solutions are used, b) effect of the secondary heat treatment temperature on the final relative density of the GDC infiltrated porous GDC scaffolds when the infiltration was carried out for 25 or 35 cycles using polymeric precursor solutions with 0.04 , 0.06 or $0.08 \mathrm{M}$ concentrations and c) impact of solution molarity on the final relative density of the 25 or 35 times GDC infiltrated porous GDC scaffolds when the final heat treatment was carried out at $1200{ }^{\circ} \mathrm{C}$. employing higher concentrations or number of cycles of solution resulted in almost no change in the relative density after sintering (Fig. 5b and c). As reported in other studies, there is a maximum amount of iron addition that is beneficial and any further additions are useless to enhance the sintering rates and may even produce microcracks in specimens [36,39-41].

\subsection{Microstructural analyses}

Scanning electron microscopy (SEM) images of the fracture surfaces of the conventionally sintered GDC pellets, given in Fig. 6, clearly shows that the amount of porosity decreases with increasing sintering temperature which is also consistent with the measured bulk densities (see Fig. 3). As can be seen in Fig. 6(g-i) almost no open porosity remains upon sintering at temperatures above $1400^{\circ} \mathrm{C}$, agreeing well with the measured relative densities exceeding $97.0 \%$. As a typical trait of
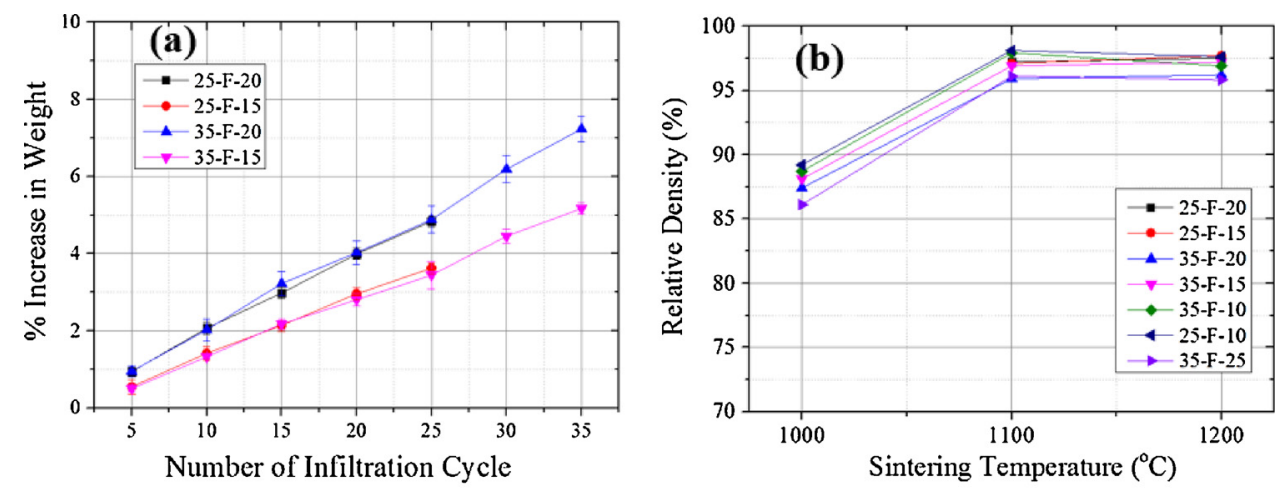

Fig. 5. a) Effect of polymeric FeOx precursor infiltration cycles on the $\%$ weight increase of the porous GDC scaffolds when 0.015 or $0.020 \mathrm{M}$ solutions are used, b) effect of the secondary heat treatment temperature on the final relative density of the $\mathrm{FeOx}$ infiltrated porous GDC scaffolds when the infiltration was carried out for 25 or 35 cycles using polymeric precursor solutions with $0.01,0.015$ or $0.020 \mathrm{M}$ concentrations and c) impact of solution molarity on the final relative density of the 25 or 35 times FeOx infiltrated porous GDC scaffolds when the final heat treatment was carried out at $1200{ }^{\circ} \mathrm{C}$.

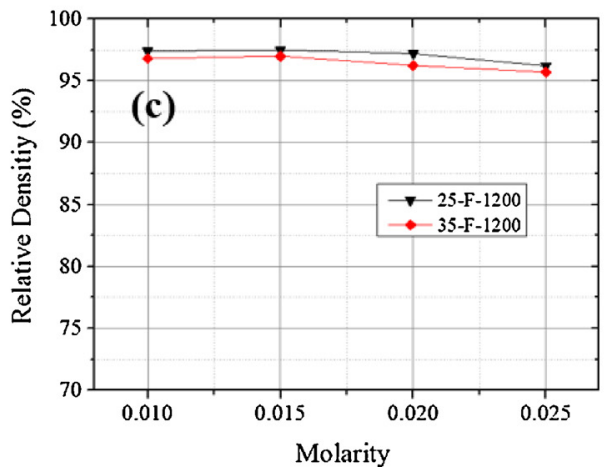



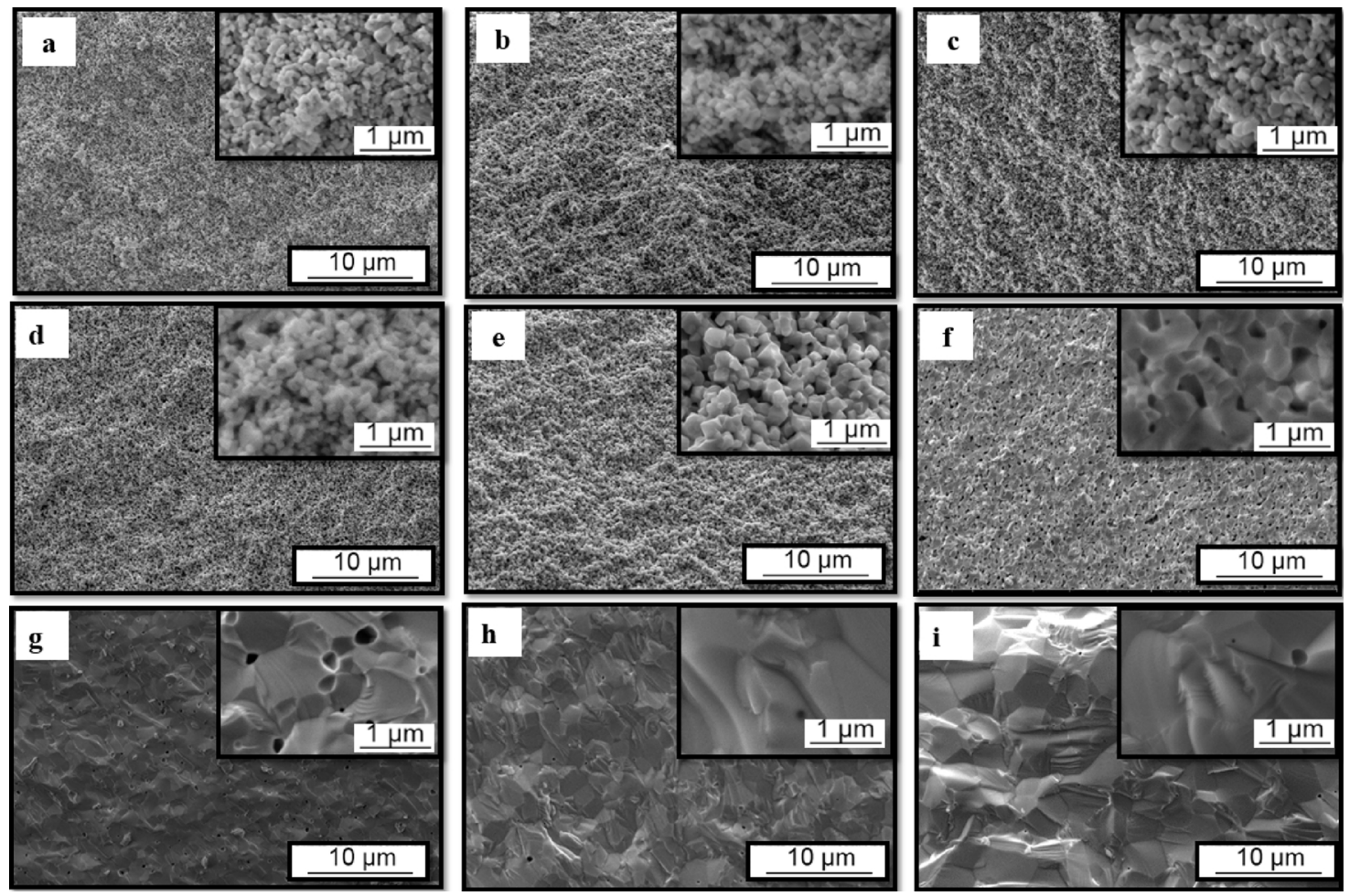

Fig. 6. Scanning electron microscopy images of the fracture surfaces of the gadolinia doped ceria pellets a) 800 b) 900 c) 1000 d) 1100 e) $1200 \mathrm{f}) 1300 \mathrm{~g}$ ) $1400 \mathrm{~h}$ ) 1450 and i) 1500 for $8 \mathrm{~h}$ in air. The insets provide higher magnification images.

Table 2

Effect of sintering temperature on gadolinia doped ceria (GDC) grain size and relative density. Standard deviations of grain sizes are given in paranthesis.

\begin{tabular}{lll}
\hline Sintering Temperature $\left({ }^{\circ} \mathrm{C}\right)$ & Grain Size $(\mathrm{nm})$ & Relative Density (\%) \\
\hline 800 & $164(30)$ & 58.2 \\
900 & $163(15)$ & 59.0 \\
1000 & $168(14)$ & 60.0 \\
1100 & $196(21)$ & 63.0 \\
1200 & $217(25)$ & 72.0 \\
1300 & $348(22)$ & 85.5 \\
1400 & $727(50)$ & 97.0 \\
1450 & $741(66)$ & 98.7 \\
1500 & $765(47)$ & 99.3 \\
\hline
\end{tabular}

solid-state sintering, densification in the present case is also accompanied by a significant grain growth (insets in Fig. 6). The average grain size (determined by the lineal intercept method) increases from 164 to $765 \mathrm{~nm}$ when the sintering temperature is raised from 800 to $1500{ }^{\circ} \mathrm{C}$, consistent with conventional solid-state sintering (Table 2). Note that much of the grain growth occurs between 1200 and $1400{ }^{\circ} \mathrm{C}$.

The impact of the number of infiltration cycles, the concentration of the polymeric GDC precursor solution and the final heat treatment temperature on the microstructure of the GDC infiltrated porous GDC scaffolds is shown in the scanning electron microscopy (SEM) images (Fig. 7). Overall, similar microstructures are observed in the SEM images taken from the upper, middle and bottom parts of the fractured pellets, suggesting that the infiltration solution penetrated equally well to all parts of the sample (Fig. 7). As the heat treatment temperature of the porous GDC scaffold infiltrated by a $0.040 \mathrm{M}$ polymeric GDC precursor solution for 25 cycles is increased from 1000 (Fig. 7a-c) to $1200{ }^{\circ} \mathrm{C}$ (Fig. $7 \mathrm{~d}-\mathrm{f}$ ) a decrease in the porosity is observed. In this case, the faster diffusion rates enabled by a higher temperature is responsible for denser microstructure. Increasing the number of infiltration cycles contributes little to the resulting sintered density (Fig. 7g-i). Concentration of infiltrating solution is, however, more effective in obtaining higher density after sintering at $1200^{\circ} \mathrm{C}$ (Fig. $\left.7 \mathrm{j}-\mathrm{l}\right)$.

Higher magnification SEM images showing the resultant grain size are given as insets in Fig. 7. The measured average grain size values in the upper, middle and bottom parts of the GDC infiltrated GDC ceramics are quite similar (Table 3 ), indicating a homogeneous distribution of the infiltrated GDC phase. An increase in the relative density from $72.6 \%$ to $95.5 \%$ corresponds to an average grain size increase from 247 to only $432 \mathrm{~nm}$ (Table 3). Conventionally sintered GDC pellets sintered at $1400{ }^{\circ} \mathrm{C}$ have similar density with those GDC infiltrated GDC ceramics sintered at $1200^{\circ} \mathrm{C}$, but at roughly twice as much grain size, thus making the latter a still more attractive process. Some groups, reported that the grain boundaries act as barriers to oxygen ion transport and hence, increasing grain size tends to enhance the electrical conductivity of GDC [45-48]. On the other hand, some groups find contradicting results, suggesting an increase in the electrical conductivity of GDC with smaller grain size [49-52]. To clarify this issue, further investigations on the effect of microstructure on the electrical conductivity of GDC ceramics is required.

To be able to track the distribution of the infiltrated phase within the porous GDC scaffold, microstructural evolution of the polymeric FeOx precursor infiltrated GDC ceramics has been investigated via SEM (Fig. 8). Similar to GDC infiltrated samples, SEM images were collected from top, middle and bottom parts of the fracture surfaces of the pellets. The microstructure appears denser when the sintering temperature of the FeOx infiltrated GDC ceramics were raised from 1000 (Fig. 8a-c) to $1200{ }^{\circ} \mathrm{C}$ (Fig. 8d-f). The achievement of dense GDC ceramics at low sintering temperatures $\left(1000-1200^{\circ} \mathrm{C}\right)$ in the presence of $\mathrm{FeOx}$ has also been reported in the literature [30,31,42-44]. No significant changes in the microstructure are observed when the molarity of the infiltration solution is raised from 0.015 (Fig. $8 \mathrm{~d}-\mathrm{f}$ ) to $0.020 \mathrm{M}$ (Fig. 8g-i) or when the number of infiltration cycles were increased from 25 (Fig. $8 \mathrm{~g}-\mathrm{i}$ ) to 35 (Fig. 8j-1).

Grain sizes measured via lineal intercept method suggest a significant grain growth with increased density. The average grain size increases from 324 to $738 \mathrm{~nm}$ when the samples are densified from 89.9 

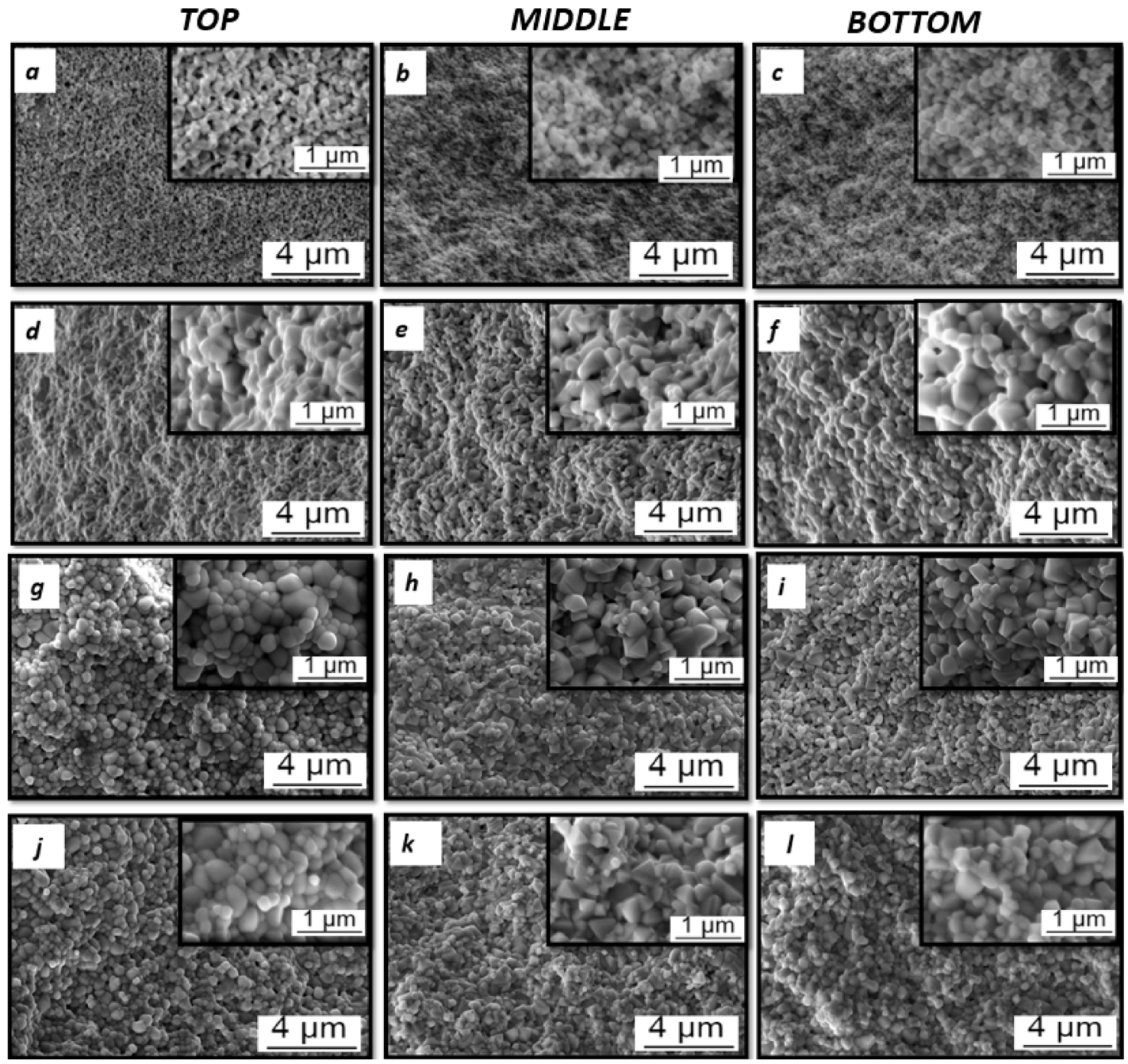

Fig. 7. Scanning electron microscopy images of the fractured surfaces of porous gadolia doped ceria (GDC) scaffolds infiltrated for 25 cycles using a $0.04 \mathrm{M}$ polymeric GDC precursor and heat treated at a-c) $1000^{\circ} \mathrm{C}(25-\mathrm{G}-40-1000)$ and d-f) $1200^{\circ} \mathrm{C}$ (25-G-40-1200) for $8 \mathrm{~h}$ in air, of porous GDC scaffolds infiltrated for 35 cycles using a g-i) $0.04 \mathrm{M}$ (35-G-40-1200) and j-1) $0.08 \mathrm{M}$ (35-G-80-1200) polymeric GDC precursor solution both sintered at $1200^{\circ} \mathrm{C}$ for $8 \mathrm{~h}$ in air. The images in the same row were taken from the top, middle and bottom sections (from left to right) of the same sample to observe the uniformity of the microstructure. The insets show higher magnification images.

Table 3

Grain size and relative densities of the gadolinia doped ceria (GDC) and the FeOx infiltrated porous GDC scaffolds. Standard deviations of grain sizes are given in paranthesis.

\begin{tabular}{|c|c|c|c|c|c|}
\hline \multirow[t]{2}{*}{ Sample Code } & \multicolumn{4}{|c|}{ Grain Size (nm) } & \multirow{2}{*}{$\begin{array}{l}\text { Relative Density } \\
(\%)\end{array}$} \\
\hline & Upper & Middle & Bottom & Ave. & \\
\hline $\begin{array}{r}25-G-40- \\
1000\end{array}$ & 243 (27) & 249 (12) & $252(24)$ & 247 (21) & 72.6 \\
\hline $\begin{array}{r}25-G-40- \\
1200\end{array}$ & 351 (58) & $343(21)$ & $363(48)$ & 352 (43) & 86.7 \\
\hline $\begin{array}{r}35-G-40- \\
1200\end{array}$ & 376 (87) & $382(73)$ & 367 (90) & 375 (84) & 87.5 \\
\hline $\begin{array}{r}35-G-80- \\
1200\end{array}$ & $442(56)$ & 434 (37) & $421(21)$ & 432 (39) & 95.5 \\
\hline $\begin{array}{r}25-F-15- \\
1000\end{array}$ & $321(21)$ & $318(20)$ & 333 (32) & 324 (25) & 89.9 \\
\hline $\begin{array}{r}25-F-15- \\
1200\end{array}$ & 705 (63) & $706(101)$ & 704 (53) & $705(72)$ & 97.4 \\
\hline $\begin{array}{r}25-\mathrm{F}-20- \\
1200\end{array}$ & 729 (99) & 751 (114) & 735 (107) & 738 (106) & 97.7 \\
\hline $\begin{array}{r}35-F-20- \\
1200\end{array}$ & $750(71)$ & 740 (69) & $735(62)$ & 741 (68) & 96.6 \\
\hline
\end{tabular}

to $97.7 \%$ relative density (Table 3 ). The difference in the grain growth regimes of the GDC and FeOx infiltrated samples accompanying densification is notable. As mentioned earlier in the text, GDC infiltration into porous GDC scaffolds promote low temperature densification by i) filling some of the pores prior to heat treatment, ii) increasing the coordination numbers of the particles and iii) providing fast diffusion pathways through the amorphous infiltrated GDC film. On the other hand, the addition of FeOx to GDC acts as a sintering aid by promoting viscous-flow sintering [53-55].

Infiltration aided-sintering at reduced temperatures may be a feasible processing technique only if the infiltrated phase is distributed homogeneously throughout the porous scaffold. Since GDC infiltration into porous GDC scaffolds would not allow the tracking of the infiltrated phase distribution by chemical analysis, polymeric FeOx precursors were used instead. The SEM-EDX line scan results shown in Fig. 9 describes the dependence of the atomic ratios of Ce, Fe and Gd cations on the distance from the top surface of the specimen encoded as 25-F-20-1200. By infiltration, Fe cation almost in the same amount of Gd has been introduced to the porous GDC scaffold (Fig. 9). It is evident that the Fe content remains unchanged throughout the ceramic, suggesting that GDC infiltration using the same type of precursor likely 
TOP
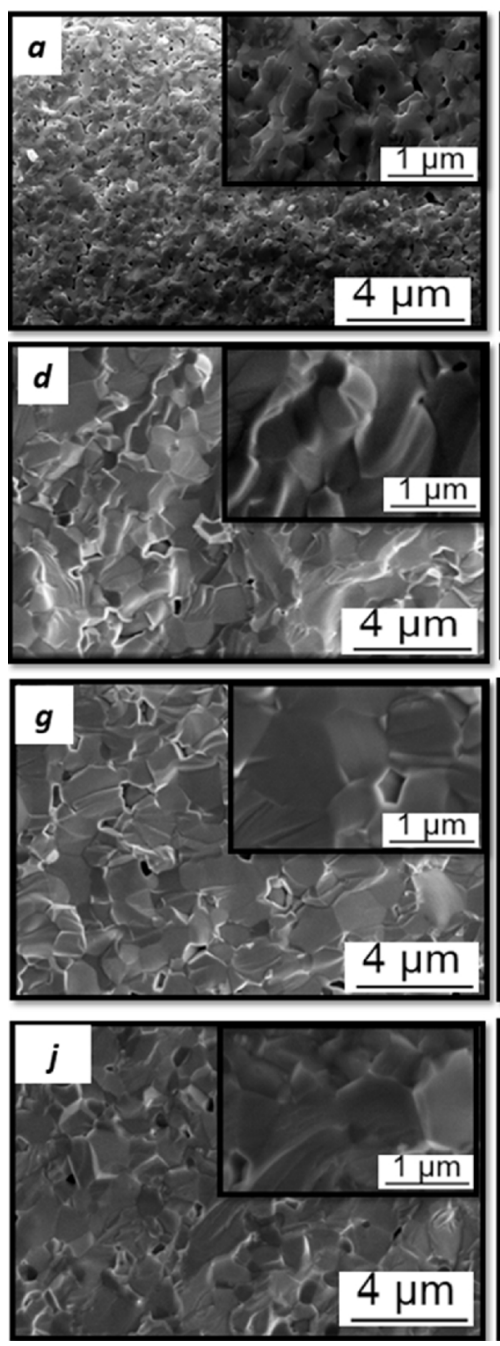

MIDDLE
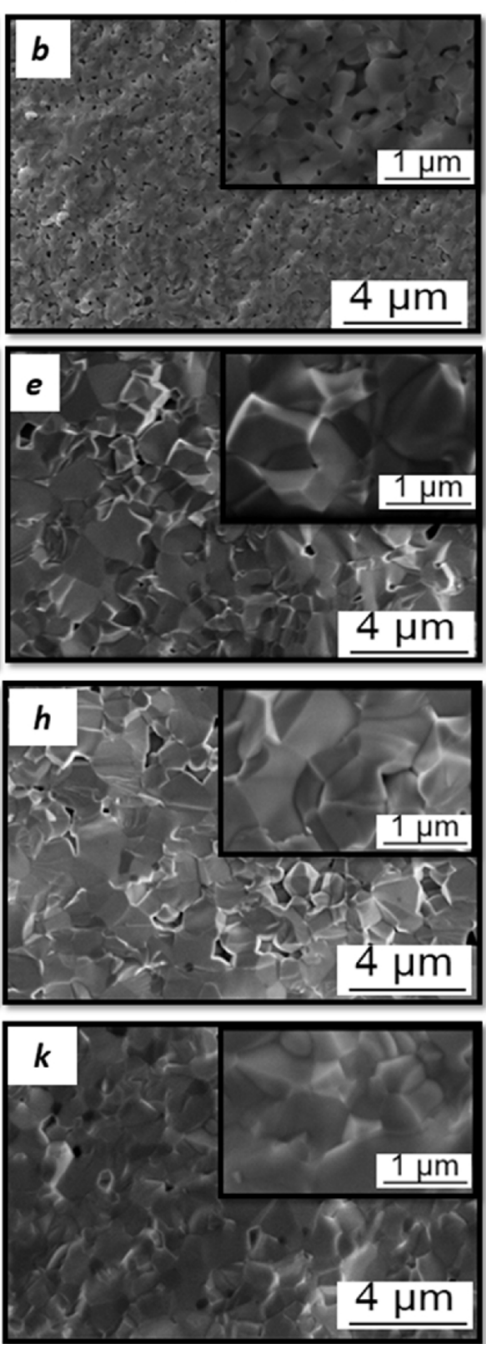

BOTTOM
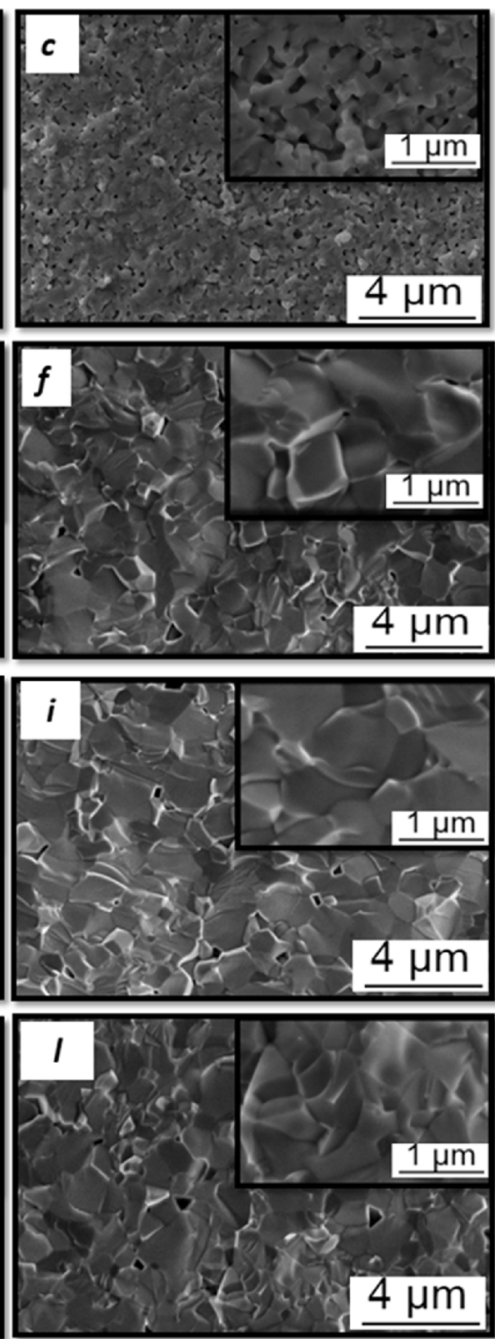

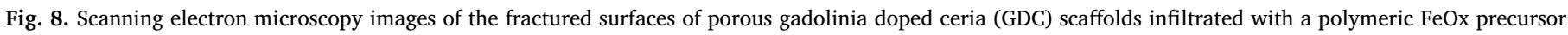

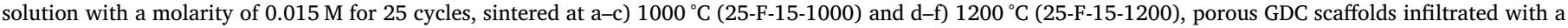

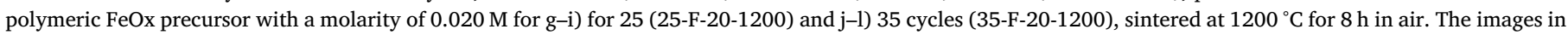

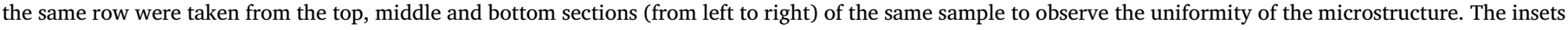
show higher magnification images.

results in a similar infiltrated phase distribution.

\section{Summary}

Gadolinia doped ceria (GDC) electrolytes need to be fully dense ( $>95 \%$ relative density) in order to ensure a gas tight solid oxide fuel cell (SOFC) and thus, high open circuit voltage. GDC is traditionally sintered above $1400{ }^{\circ} \mathrm{C}$, setting the anode sintering temperature at the same value for anode-supported cells. This results in coarse anode microstructures and thus poor SOFC performance. However, in this study, we offered and successfully demonstrated a method by which densification can be achieved at significantly lower sintering temperatures down to $1200^{\circ} \mathrm{C}$ with no additives that might influence the electrical properties. First a porous scaffold of GDC was produced by sintering at $1000^{\circ} \mathrm{C}$ before infiltration was performed in order to fill these pores by a polymeric precursor that contains Ce and Gd cations. This way, formation of an amorphous film on the particles of GDC and thus, i) partial filling of the pores prior to sintering, ii) increasing the coordination number of the scaffold particles and formation of fast diffusion routes were aimed. As far as infiltration by Ce and Gd is concerned, the use of enriched infiltrating solution and increased number of cycles both enhanced densification, yielding a relative density of $95.5 \%$ after sintering at $1200{ }^{\circ} \mathrm{C}$. Due to the lowered sintering temperatures, the dense microstructure consisted of grains with an average diameter of $432 \mathrm{~nm}$ - a much smaller value than observed in the conventionally sintered GDC ceramics with a similar density $(727 \mathrm{~nm})$.

FeOx infiltration into porous GDC scaffolds were also performed to be able to track the distribution of the infiltrated phase within the ceramic. FeOx, as reported in the literature [9,36,39-41,44], acted as a sintering aid which allowed densification at temperatures as low as $1100{ }^{\circ} \mathrm{C}$ (relative density $>97.7 \%$ ). The scanning electron microscopyenergy dispersive $\mathrm{x}$-ray spectroscopy line scan analyses showed that the Fe distribution within the GDC ceramic was very uniform, suggesting a similar situation in the case of GDC infiltration.

\section{Acknowledgements}

This project is supported by TUBITAK (The Scientific Research Council of Turkey) through project no. 116R072. Authors would like to thank different labs in both Izmir Institute of Technology and Gebze Technical University for their helps during analysis of samples. 


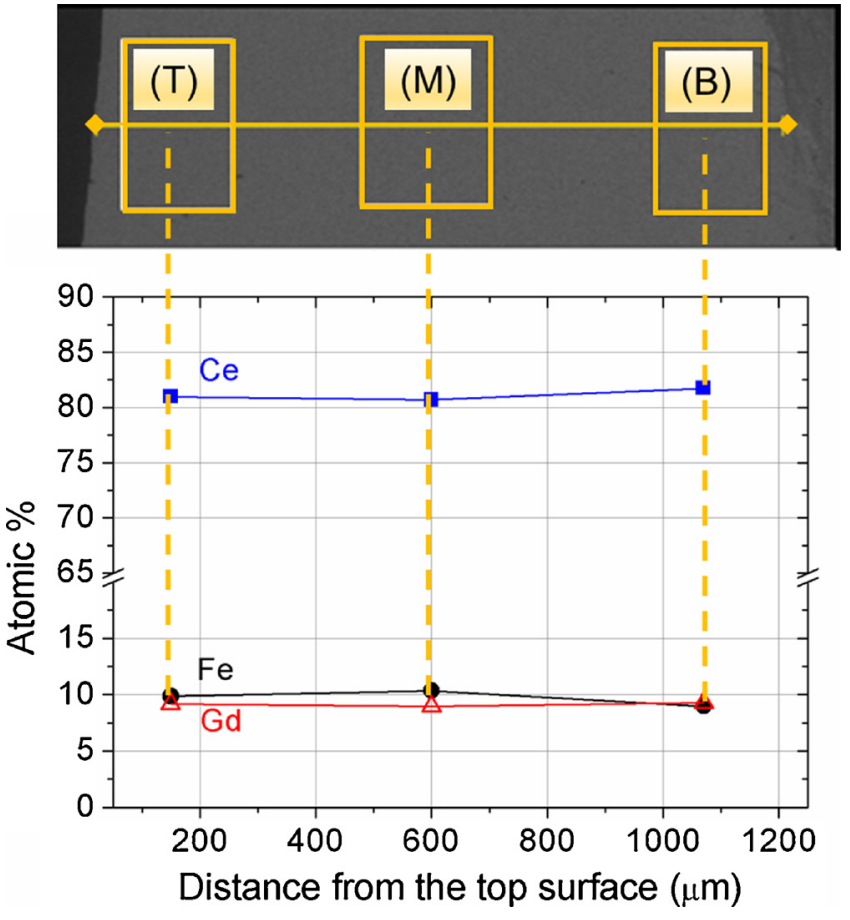

Fig. 9. Change in the atomic ratios of $\mathrm{Fe}, \mathrm{Ce}$ and Gd cations in the $\mathrm{FeOx}$ infiltrated gadolinia doped ceria (GDC) ceramic which yielded a highest relative density of $97 \%$ (sample code: 25-F-15-1100-8.) with distance from the top surface, obtained from energy disperive x-ray spectroscopy (EDX) analyses. The regions where EDX measurements were collected are labelled as the «T», «M» and «B» on the scanning electron microscopy image of the cross-section of the sample and denote top, middle and bottom sections respectively.

\section{References}

[1] M. Morales, J.J. Roa, J. Tartaj, M. Segarra, J. Eur. Ceram. Soc. 36 (1) (2016) 1-16.

[2] C. Sindirac, S. Akkurt, Int. J. Hydrogen Energy 41 (40) (2016) 18157-18165.

[3] X. Wang, Z. Chen, A. Atkinson, J. Eur. Ceram. Soc. 33 (2013) 13-14 2539-2547.

[4] S.C. Singhal, K. Kendall, High-temperature Solid Oxide Fuel Cells Fundamentals, Design and Applications, Elsevier, Burlington, 2003.

[5] N.Q. Minh, J. Am. Ceram. Soc. 76 (3) (1993) 563-588.

[6] A. Tarancón, Energies 2 (2009) 1130-1150.

[7] R.N. Basu, G. Blass, H.P. Buchkremer, D. Stoev, F. Tietz, E. Wessel, I.C. Vinke, J. Eur. Soc. 25 (4) (2005) 463-471.

[8] S.P.S. Badwal, Solid State Ion. 52 (1-3) (1992) 23-32.

[9] T.S. Zhang, J. Ma, Y.J. Leng, S.H. Chen, P. Hing, J.A. Kilner, Solid State Ion. 168 (2004) 187-195.

[10] D.P. Fagg, V.V. Kharton, J.R. Frade, J. Electroceramics 9 (2002) 199-207.

[11] B.C.H. Steele, J. Mater. Sci. 36 (5) (2001) 1053-1068.

[12] R.N. Blumenthal, F.S. Brugner, J.E. Garnier, J. Electrochem. Soc. 120 (1973) 1230.

[13] A. Selcuk, A. Atkinson, J. Eur. Ceram. Soc. 17 (12) (1997) 1523-1532.

[14] R. Gerhard-Anderson, A.S. Nowick, Solid State Ion. 5 (1981) 547.
[15] J.A. Kilner, Solid State Ion. 8 (1983) 201.

[16] S. Taub, R.E.A. Williams, X. Wang, D.W. McComb, J.A. Kilner, A. Atkinson, Acta Mater. 81 (2014) 128-140.

[17] H. Inaba, T. Nakajima, H. Tagawa, Solid State Ion. (1998) 106-163.

[18] R.S. Torrens, N.M. Sammes, G.A. Tompsett, Solid State Ion. 111 (1998) 9.

[19] K.R. Reedy, K. Karan, J. Electroceramics 15 (2005) 45-56.

[20] C. Kleinlogel, L.J. Gauckler, Solid State Ion. 135 (2000) 567.

[21] M. Mori, E. Suda, B. Pacaud, K. Murai, T. Moriga, J. Power Sources 157 (2006) $688-694$

[22] Y. Zho, M.N. Rahaman, Acta Mater. 45 (1997) 3635-3639.

[23] D.H. Prasad, J.H. Lee, H.W. Lee, B.K. Kim, J.S. Park, J. Ceramic Process. Res. 11 (5) (2010) 523-526.

[24] K. Sato, J. Appl. Phys. 51 (2012) 077301.

[25] A. Buyukaksoy, V. Petrovsky, F. Dogan, J. Electrochem. Soc. 159 (1) (2012) B67-B71.

[26] J.M. Vohs, R.J. Gorte, Adv. Mater. 21 (2009) 943-956.

[27] S. Park, R.J. Gorte, J.M. Vohs, J. Electrochem. Soc. 148 (2001) A443-A447.

[28] T.Z. Sholklapper, C. Lu, C.P. Jacobson, S.J. Visco, L.C. De Jonghe, Electrochem. Solid-State Lett. 9 (2006) A37-378.

[29] S.P. Jiang, Int. J. Hydrogen Energy 37 (2012) 449-470.

[30] J.D. Nicholas, L.C. De Jonghe, Solid State Ion. 178 (2007) 1187-1194.

[31] T.S. Zhang, J. Ma, Y.J. Leng, Z.M. He, J. Cryst. Growth 274 (2005) 603-611.

[32] A. Buyukaksoy, V.I. Birss, J. Power Sources 307 (2016) 449-453.

[33] H.U. Anderson, M.M. Nasrallah, C.-C. Chen, U.S. Patent 5, 1996, 494, 700.

[34] A. Buyukaksoy, S.P. Kammampata, V.I. Birss, J. Power Sources 287 (2015) 349-358.

[35] ASTM C20-00(2015), Standard Test Methods for Apparent Porosity, Water Absorption, Apparent Specific Gravity, and Bulk Density of Burned Refractory Brick and Shapes by Boiling Water, ASTM International, West Conshohocken, PA, 2015www.astm.org.

[36] T.S. Zhang, J. Ma, H.T. Huang, P. Hing, Z.T. Xia, S.H. Chan, J.A. Kilner, Solid State Sci. 5 (2003) 1505.

[37] M.G. Chourashiya, J.Y. Patil, S.H. Pawan, L.D. Jadhav, Mater. Chem. Phys. 109 (109) (2008) 39-44.

[38] S.P.S. Badwal, D. Fini, F.T. Ciacchi, C. Munnings, J.A. Kimpton, J. Drennan, J Mater. Chem. A 1 (36) (2013) 10768.

[39] T.S. Zhang, J. Ma, L.B. Kong, S.H. Chan, P. Hing, J.A. Kilner, Solid State Ion. 167 (2004) 203-207.

[40] T.S. Zhang, P. Hing, H.T. Huang, J.A. Kilner, J. Mater. Sci. 37 (2002) 997.

[41] T.S. Zhang, L.B. Kong, Z.Q. Zeng, H.T. Huang, P. Hung, Z.T. Xia, J.A. Kilner, J. Solid State Electrochem. 7 (2003) 348

[42] Q. Dong, Z.H. Du, T.S. Zhang, J. Lu, X.C. Song, J. Ma, Int. J. Hydrogen Energy 34 (2009) 7903-7909.

[43] P. Limthonghul, P. Jivaganent, W. Loyma, N. Pannaram, S. Charojrochkul, ECS Trans. 25 (2) (2009) 1555-1563.

[44] T.S. Zhang, J. Ma, S.H. Chan, J.A. Kilner, Solid State Ion. 176 (2005) 377-384.

[45] A. Hara, Y. Hirata, S. Sameshima, N. Matsunaga, T. Horita, J. Ceram. Soc. Jpn. 116 (2) (2008) 291-297.

[46] G.M. Christie, F.P.F. van Berkel, Solid State Ion. 83 (1996) 17-27.

[47] A. Tschöpe, E. Sommer, R. Birringer, Solid State Ion. 139 (2001) 255-265.

[48] A. Tschöpe, R. Birringer, J. Electroceramics 7 (2001) 169-177.

[49] A. Pandiyan, S.B.K. Moorthy, Nanomater. Energy 1 (2012) 288-305.

[50] V. Singh, S. Babu, A.S. Karakoti, A. Agarwal, S. Seal, J. Nanosci. Nanotechnol. 10 (2010) 1-9.

[51] G. Baldinozzi, D. Simeone, D. Gosset, M. Dollé, G. Petot- Ervas, Mrs Proc. 1122 (2008) 1122-006-02

[52] X.D. Zhou, W. Huebner, I. Kosacki, H.U. Anderson, J. Am. Ceram. Soc. 85 (7) (2002) $1757-1762$.

[53] J.P. Bonnet, N. Dolet, J.M. Heintz, J. Eur. Ceram. Soc. 16 (1996) 1163.

[54] J.A. Varela, J. Am. Ceram. Soc. 79 (1996) 789.

[55] G.S. Lewis, A. Atkinson, B.C.H. Steele, J. Drennan, Solid State Ion. 152-153 (2002) 567. 